\title{
Vénus Khoury-Ghata, La revenante
}

\section{Ilaria Vitali}

\section{OpenEdition}

\section{Journals}

\section{Edizione digitale}

URL: http://journals.openedition.org/studifrancesi/7074

DOI: $10.4000 /$ studifrancesi. 7074

ISSN: 2421-5856

\section{Editore}

Rosenberg \& Sellier

\section{Edizione cartacea}

Data di pubblicazione: 1 septembre 2010

Paginazione: 421

ISSN: 0039-2944

\section{Notizia bibliografica digitale}

Ilaria Vitali, «Vénus Khoury-Ghata, La revenante», Studi Francesi [Online], 161 (LIV | II) | 2010, online dal 30 novembre 2015, consultato il 07 janvier 2021. URL: http://journals.openedition.org/studifrancesi/ 7074 ; DOI: https://doi.org/10.4000/studifrancesi.7074

Questo documento è stato generato automaticamente il 7 janvier 2021.

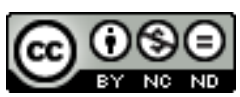

Studi Francesi è distribuita con Licenza Creative Commons Attribuzione - Non commerciale - Non opere derivate 4.0 Internazionale. 


\title{
Vénus Khoury-Ghata, La revenante
}

\author{
Ilaria Vitali
}

\section{NOTIZIA}

VÉNUS KHOURY GHATA, La revenante, Paris, L’Archipel, 2009, p. 203.

1 Il Medio Oriente, con il suo ricco bagaglio di storie e leggende, è da sempre uno dei motivi ispiratori della prosa di Vénus Khoury-Ghata. La revenante, ultima opera dell'autrice franco-libanese, intende trasportare il lettore in una Siria in bilico tra avvenimenti storici, superstizione e fantasia. Prendendo spunto da una storia vera, il romanzo racconta lo straordinario destino di Laura, pediatra parigina la cui vita cambia di colpo quando, un giorno, legge sul giornale la notizia del ritrovamento dei corpi di tre archeologi francesi sepolti nel Gebel Druso nel 1949. Al misterioso ritrovamento si aggiunge un altro enigma: uno dei tre corpi, ritrovati sotto le rovine di un tempio, è quello di una donna, Nora. Improvvisamente, Laura si dice certa di esserne la reincarnazione. Decide così di partire per il Medio Oriente e di lanciarsi in una quête identitaria ed esistenziale. Ricalcando le orme di Nora cinquant'anni dopo la sua morte, Laura si trova catapultata in un Oriente dai colori e profumi leggendari, che richiamano a tratti un altro romanzo di Khoury-Ghata, anch'esso ambientato nel Vicino Oriente, Bayarmine.

2 In una narrazione volutamente barocca, Khoury-Ghata sovrappone con grande abilità la vita di Nora e quella di Laura, ponendo il lettore all'incrocio di due destini separati e allo stesso tempo condivisi. L'autrice è soprattutto una conteuse: non c'è, nel romanzo, volontà di precisione scientifica o un eccessivo interesse per la credibilità degli eventi narrati; come lei stessa ha dichiarato nella sua «autobiografia»: «je suis un écrivain paresseux [...]. Je ne me documente pas, ni ne prends des notes, ni n'écoute les conversations dans les cafés. Ce que j'appelle mes romans est écrit impulsivement comme on crie» (La maison aux orties, 2008, p. 18); ancora una volta, c'è, in questo romanzo, la scrittura visionaria dell'autrice, che per l'occasione veste i panni di una surreale archeologa-detective, risolvendo un mistero che sfugge e si complica pagina 
dopo pagina, quasi come in un romanzo giallo. Laura è davvero Nora? A svelare l'enigma saranno le innumerevoli storie, leggende, parabole che s'intrecciano sullo sfondo di un Oriente fantastico e lussureggiante, a tratti stravagante e beffardamente inverosimile. Linea guida - per non far perdere il lettore in un labirinto di analessi e prolessi - la riflessione sulla dualità: del sogno e del reale, della stabilità e dell'erranza, del radicamento e dell'esilio. Firmando questo romanzo, la sua trentanovesima opera letteraria, Vénus Khoury-Ghata continua la riflessione sui temi che da sempre caratterizzano la sua produzione: primo fra tutti la morte, non percepita come qualcosa di distante dalla vita, ma piuttosto come un suo surreale proseguimento parallelo. Come in altre opere - ricordiamo soltanto Mortemaison (1986), Une maison au bord des larmes (1998), La maison aux orties - anche qui il mondo dei morti e quello dei vivi s'intrecciano in maniera indissolubile e la figura del revenant incarna alla perfezione il passaggio dall'uno all'altro; un transito doloroso, che lascia spesso ferite e questioni irrisolte. La revenante si chiude infatti su una serie di domande, punti in sospeso che riguardano il passato e il futuro dei numerosi personaggi che riempiono le pagine del romanzo. Che ne sarà di loro, una volta che l'autrice ha scritto l'ultima pagina? Al lettore il compito di trovare le risposte. 